\title{
The Pharmacodynamics Study of Insect Defensin DLP4 Against Toxigenic Staphylococcus hyicus ACCC 61734 in Vitro and Vivo
}

\author{
Xuanxuan Ma ${ }^{1,2}$, Na Yang ${ }^{1,2}$, Ruoyu Mao ${ }^{1,2}$, Ya Hao $^{1,2}$, Xue Yan ${ }^{3}$, Da Teng ${ }^{1,2 *}$ \\ and Jianhua Wang ${ }^{1,2 *}$ \\ ${ }^{1}$ Gene Engineering Laboratory, Feed Research Institute, Chinese Academy of Agricultural Sciences, Beijing, China, \\ ${ }^{2}$ Key Laboratory of Feed Biotechnology, Ministry of Agriculture and Rural Affairs, Beijing, China, ${ }^{3}$ New Hope Liuhe Co., Ltd., \\ Quality Control for Feed and Products of Livestock and Poultry Key Laboratory of Sichuan Province, Chengdu, China
}

\section{OPEN ACCESS}

Edited by:

Alejandra Ochoa-Zarzosa, Michoacana University of San Nicolás de Hidalgo, Mexico

Reviewed by:

José E. Barboza-Corona, University of Guanajuato, Mexico Marina Sabaté Brescó,

University Clinic of Navarra, Spain

*Correspondence: Jianhua Wang wangjianhua@caas.cn; 2681298635@qq.com Da Teng

tengda@caas.cn

Specialty section:

This article was submitted to

Bacteria and Host

a section of the journal

Frontiers in Cellular and Infection Microbiology

Received: 07 December 2020 Accepted: 15 April 2021 Published: 05 May 2021

Citation:

Ma $X$, Yang $N$, Mao $R$, Hao $Y$, Yan X, Teng D and Wang J (2021) The Pharmacodynamics Study of

Insect Defensin DLP4 Against Toxigenic Staphylococcus hyicus ACCC 61734 in Vitro and Vivo. Front. Cell. Infect. Microbiol. 11:638598. doi: 10.3389/fcimb.2021.638598
Staphylococcus hyicus (S. hyicus), as the main pathogen of exudative epidermitis (EE) in piglet, can cause a wide variety of diseases, ranging from bovine mastitis, chicken arthritis and even human sepsis, which has brought serious threats to animals and human. The potential threat of $S$. hyicus infection to both public and animal health has aroused great concern. The aim of our study was to explore the efficacy of insect defensin DLP4 against S. hyicus ACCC 61734 in vitro and in vivo. The in vitro efficacies of DLP4 against S. hyicus ACCC 61734 showed high antibacterial activity $(0.92 \mu \mathrm{M})$, a long postantibiotic effect (9.54 h), a synergistic effect with ceftriaxone, penicillin and amoxicillin, a stable bacteriostatic effect, and intracellular bacteriostatic activity against S. hyicus ACCC 61734 in HaCaT cells. Besides, the antibacterial mechanism of DLP4 against S. hyicus ACCC 61734 was explored for the first time, which indicated that the antibacterial effect of DLP4 was related to its ability to destroy cell wall and generate membrane vesicles. The in vivo therapeutic effect of DLP4 was evaluated through mouse abscess model, and the results showed that DLP4 could effectively alleviate the mouse skin abscess by inhibiting bacterial proliferation and regulating cytokines. This study first demonstrated that DLP4 may be a promising therapeutic agent against S. hyicus ACCC 61734 infection.

Keywords: S. hyicus, insect defensin DLP4, in vitro antibacterial activity, antibacterial mechanism, in vivo therapeutic effect

\section{INTRODUCTION}

Exudative epidermitis (EE), also known as "greasy pig disease", is an occasional and contagious skin disease, which predominantly infects weaning and newborn piglet (Olivry and Linder, 2009). Staphylococcus hyicus was widely acknowledged as the major causative agent of EE, it can produce up to six various 27-30 KDa exfoliation toxins (ExhA, ExhB, ExhC, ExhD, ShetA, and ShetB), which was always considered as the key pathogenic factor of EE (Andresen et al., 1993; Andresen and Ahrens, 2004). Previous studies have revealed that the four Exh exfoliation toxins and ShetB belong to serine proteases family, whose amino acid sequences are highly homologous with the exfoliative 
toxins (ETA, ETB, and ETD) of Staphylococcus aureus, especially in the vicinity of the active sites. Besides, like exfoliative toxins (ETs), Exh can specifically recognize and digest desmoglein 1 (Dsg1) (Fudaba et al., 2005; Nishifuji et al., 2005), causing the separation of cells in the upper stratum spinosum, forming typical symptoms of dermatitis, these symptoms all indicated that they have similar pathophysiological functions in animals and human (Hanakawa et al., 2002; Nishifuji et al., 2008; Mariutti et al., 2015). Recently, the outbreak of EE in worldwide has brought huge economic losses to the breeding industry (Arsenakis et al., 2018), and the prevention and treatment of EE have increasingly attracted widespread attention.

Presently, with the wide-ranging inappropriate use of antibiotics, multidrug resistant $S$. hyicus has been isolated from piglets around the world (Holmer et al., 2019). Previous tests showed that among 142 strains isolated from Canada, the strains with penicillin $\mathrm{G}$, ampicillin, ceftiofur, and tetracycline resistance accounted for 90, 90, 70, and 55.6\%, respectively (Park et al., 2013), and the strains isolated from Korean developed remarkable resistance to amoxicillin, lincomycin, penicillin, streptomycin, and tetracycline (Park et al., 2018). Besides, the isolated S. hyicus ACCC 61734 has also been proved to develop resistance to penicillin, sulfamethoxazole, chloramphenicol, streptomycin, azithromycin, erythromycin, tetracycline, bacitracin and norfloxacin in our previous study (Ma et al., 2019). Given the increasing acquisition of antibiotic resistance by pathogens, the prevention and control of S. hyicus infection have been a huge challenge, which indicates an urgent need for new effective antibacterial drugs. Antimicrobial peptides (AMPs), as a critical part of the natural defense system, are small cationic peptides with extensive antibacterial activity and have been considered as an alternative to traditional antimicrobial agents for their high antibacterial activity and low resistance (Hancock and Sahl, 2006). According to our previous study, DLP4, as an insect defensin from Hermetia illucens, presented a broadspectrum antibacterial activity against gram-positive bacteria, and had no significant hemolytic activity to mice erythrocytes $(1.46 \%$ at $512 \mu \mathrm{g} / \mathrm{ml})$ or moderate cytotoxicity to mouse peritoneal macrophages $(17.39 \%$ at $128 \mu \mathrm{g} / \mathrm{ml})$. Meanwhile, DLP4 was difficult to develop resistance due to its unique antibacterial mechanism (Li et al., 2017). All these results indicated that DLP4 may be considered to be a promising drug for treating S. hyicus infections.

Based on our previous research on the antibacterial effects of DLP4 on S. aureus, this study systematically explored the in vitro antibacterial properties and mechanisms of DLP4 against $S$. hyicus ACCC 61734. In addition, the in vivo efficacies of DLP4 were confirmed using mouse abscess model caused by $S$. hyicus ACCC 61734.

\section{MATERIALS AND METHODS}

\section{Materials}

S. hyicus NCTC 10350 was purchased from National Collection of Type Culture (NCTC). Clinical strain S. hyicus ACCC 61734 was isolated from the kidney of a piglet with defined EE by Tianjin Animal Science and Veterinary Research Institute. DLP4 was prepared as described in our previous study (Li et al., 2017). Six-week-old female BALB/c mice (SPF) were purchased from the Vital River Laboratories (VRL, Beijing, China). All other chemical reagents were of analytical grade. All animal researches have been approved by the Animal Care and Use Committee of the Feed Research Institute of the Chinese Academy of Agricultural Sciences (CAAS).

\section{Antibacterial Assay In Vitro \\ Antimicrobial Activity Determination}

The minimum inhibitory concentrations (MICs) of DLP4 against S. hyicus ACCC 61734 and S. hyicus NCTC 10350 were determined using the microtiter broth dilution method described previously (Zhang et al., 2014). The mid-log phase bacteria were diluted to $1 \times 10^{5} \mathrm{CFU} / \mathrm{ml}$ with fresh MHB medium, a total of 90 $\mu \mathrm{l}$ of cell suspension and $10 \mu \mathrm{l}$ of serially twofold diluted peptide with the final concentrations of $0.0625-128 \mu \mathrm{g} / \mathrm{ml}$ were added into 96 -well plates. The plates were incubated for $18-24 \mathrm{~h}$ at $37^{\circ} \mathrm{C}$. The MIC value was determined as the lowest peptide concentration at which no bacterial growth was observed. Ceftriaxone, ceftiofur, ofloxacin, and amoxicillin were used as controls. All assays were performed in triplicate.

\section{Growth Kinetic Assays}

Growth kinetic determination was performed in order to estimate the pharmacodynamics of DLP4 against S. hyicus ACCC 61734. The tested strains were diluted to $10^{5} \mathrm{CFU} / \mathrm{ml}$ and mixed with different concentrations of peptide at final peptide concentrations of $1 \times, 2 \times$, or $4 \times$ MIC, respectively, and then were incubated at $37^{\circ} \mathrm{C}$. After $0,0.5,1,2,4,8,10,12$, and $24 \mathrm{~h}$ incubation, the samples $(100 \mu \mathrm{l})$ were taken for colony counting on MHA plates. Ceftriaxone and $0.9 \% \mathrm{NaCl}$ were used as positive and blank controls, respectively (Zhang et al., 2014).

\section{The Postantibiotic Effect (PAE) of DLP4 Against $S$. hyicus}

PAE assays of DLP4 against S. hyicus ACCC 61734 were manipulated and calculated as previously described (Zhao et al., 2019). The specific steps are described as follows: (1) PAE induction stage: Tested strain S. hyicus ACCC 61734 was diluted to $10^{8} \mathrm{CFU} /$ $\mathrm{ml}$ and mixed with corresponding concentration of DLP4 at final concentrations of $1 \times, 2 \times$, or $4 \times$ MIC, respectively, then were incubated at $37^{\circ} \mathrm{C}$ for $2 \mathrm{~h}, 2 \times$ MIC ceftriaxone and PBS were used as positive and blank control, respectively; (2) Drug removal and reconstruction: each of the above systems was diluted 1,000 times to remove the drug and reconstruct the growth system, which was defined at this point as the $0 \mathrm{~h}$ point after reconstruction; (3) Colony counting: the above reconstructed system was incubated at $37^{\circ} \mathrm{C}$, and the bacterial colonies were counted at $0,2,4,6,8,10,12,20,22$, and $24 \mathrm{~h}$ by sampling gradient dilutions, respectively; (4) PAE calculation: PAE $(\mathrm{h})=\mathrm{T}-\mathrm{C}, \mathrm{T}$ : time required for the number of colonies in the drug-treated group to be 10 times as the number of colonies at $0 \mathrm{~h}, \mathrm{C}$ : corresponding time required for the blank control group. 


\section{Synergistic Interactions of DLP4 With Other Antibiotics}

The possible synergistic effects of DLP4 in combination with penicillin, ceftriaxone, amoxicillin and ofloxacin were performed using the checkerboard method. The specific steps are described as follows: An $80 \mu \mathrm{l}$ of S. hyicus ACCC $61734\left(10^{8} \mathrm{CFU} / \mathrm{ml}\right)$ was added into the 96-well plate, and then $10 \mu \mathrm{l}$ of DLP4 and antibiotics were added into the above 96-well plate at a final concentration of $1 / 16$ to $8 \times$ MIC in the horizontal and vertical directions, respectively. Finally, the 96 -well plate was incubated at $37^{\circ} \mathrm{C}$ for $18 \mathrm{~h}$. The optimal drug combination and concentration was determined based on the FICI. FICI determination criteria: FICI $\geq 4$ : antagonistic effect, $1<$ FICI $\leq 4$ : irrelevant effect; $0.5<$ FICI $\leq 1$ : additive effect; and FICI $\leq 0.5$ : synergistic effect (Zheng et al., 2017).

\section{Resistance Induction Test}

To speculate whether the long-term use of antimicrobial agents could cause the bacteria to develop corresponding drug resistance, S. hyicus ACCC 61734 cells were exposed to subMIC concentration of DLP4 or ceftriaxone, and incubated for $30 \mathrm{~d}$, then used for continuous MIC measurement (Narayana et al., 2015; Li et al., 2017).

\section{Intracellular Bacteriostatic Efficacy}

To investigate the intracellular antibacterial effect of DLP4, the invasion assay was firstly operated as described previously (Wang et al., 2018b). In brief, HaCaT cells $\left(2.5 \times 10^{5}\right.$ cells, $\left.750 \mu \mathrm{l}\right)$ were inoculated into 12-well, after incubation for $24 \mathrm{~h}$ in minimum Eagle's medium (MEM) with $10 \%$ FBS (without antibiotics), The mid-log phase S. hyicus ACCC 61734 cells were added into the plates at a concentration of $2.5 \times 10^{7} \mathrm{CFU} / \mathrm{ml}$ in MEM with $10 \%$ FBS (without antibiotic) and incubated for $30 \mathrm{~min}$, gentamicin $(100 \mu \mathrm{g} / \mathrm{ml})$ was added and incubated for $2 \mathrm{~h}$ to remove extracellular bacteria. After washing with $\mathrm{PBS}, \mathrm{HaCaT}$ cells were fixed in $2.5 \%$ glutaraldehyde overnight at $4^{\circ} \mathrm{C}$, postfixed with $1 \%$ osmium tetroxide $\left(\mathrm{OsO}_{4}\right)$, dehydrated in a gradient ethanol series, then cells were immersed in epoxy resin; the ultramicrotome was used to acquire the thin sections, followed by staining with $1 \%$ uranyl acetate. Images were visualized by a TEM (JEM1400, JEDL, Japan); (2) HaCaT cells were treated with different concentrations of DLP4 $(5 \times, 10 \times$, and $50 \times$ MIC) for $24 \mathrm{~h}$, washed again and lysed with Hanks buffered saline solution $(0.1 \%$ bovine serum albumin and $0.1 \%$ Triton-X). The numbers of intracellular bacteria were measured at 0 and $24 \mathrm{~h}$ by colony counting.

\section{The Antibacterial Mechanism of DLP4 Membrane Permeabilization Assays}

The influence of DLP4 on S. hyicus ACCC 61734 cell membrane was determined using the DNA intercalating dye propidium iodide (PI) uptake assay by flow cytometry (Zheng et al., 2017). S. hyicus ACCC 61734 cells in mid-log phase $\left(1 \times 10^{8} \mathrm{CFU} / \mathrm{ml}\right)$ were treated with DLP4 $(1 \times, 2 \times$, and $4 \times \mathrm{MIC})$ at $37^{\circ} \mathrm{C}$ for 5,30 and $120 \mathrm{~min}$, respectively. After staining with PI, the samples were analyzed by a Flow Cytometer (FACS Calibur, BD, USA).

\section{Electron Microscopy Observations}

Mid-log phase S. hyicus ACCC 61734 cells, were treated with $4 \times$ MIC DLP4 for $2 \mathrm{~h}$ at $37^{\circ} \mathrm{C}$. Subsequently, the samples were fixed with $2.5 \%$ glutaraldehyde overnight at $4^{\circ} \mathrm{C}$, dehydrated in a gradient ethanol series, and dried with $\mathrm{CO}_{2}$. Finally, the samples were sputtered using gold-palladium and observed under a QUANTA200 scanning electron microscope (SEM), (FEI, Philips, Netherlands) (Hao et al., 2017).

Transmission electron microscopy (TEM) was used for further observations of the cell morphology and intracellular changes. Bacterial samples were treated using the same method as described above (Hao et al., 2017). After postfixation with 1\% $\mathrm{OsO}_{4}$ and gradient dehydration, cells were embedded in resin, sliced, and placed on a formvar carrier grid, followed by uranyl acetate and lead citrate treatments. Microscopy was performed using a TEM (JEM1400, JEDL, Japan).

\section{Mouse In Vivo Test}

To evaluate the in vivo efficacy of DLP4, the mouse abscess model was established. Six-week-old female BALB/c mice were randomly allocated into four groups (20 mice/group) including blank control (uninfected and untreated), negative control (infected but untreated) and two treated group (infected and treated with DLP4 and ceftriaxone, respectively). All mice were anesthetized and shaved on the abdomen. Next, the mice were subcutaneously injected with $200 \mu \mathrm{l}$ of the exponential phase S. hyicus ACCC $61734\left(2.5 \times 10^{9} \mathrm{CFU} / \mathrm{ml}\right)$ (Ding et al., 2012; Wang et al., 2018a), after infection for $24 \mathrm{~h}$, DLP4 (150 $\mathrm{gg}$ /flank) or ceftriaxone (600 $\mu \mathrm{g} /$ flank) was injected subcutaneously near the abdomen once a day for $3 \mathrm{~d}$. During the period of treatment, the clinical wound sites were imaged and further measured by Image $J$ to record abscess area. After infection for 3, 7, and $12 \mathrm{~d}$, mice were euthanized and skin tissue samples were collected, weighed and homogenized, then the suspension of abscesses was serially diluted in sterile PBS for colony counting. Additionally, the levels of inflammatory factors interleukin-6 (IL-6) and tumor necrosis factor- $\alpha$ (TNF- $\alpha$ ), and epidermal growth factor (EGF) released from abscesses were measured by ELISA kit. At the same time, the abscess samples of mice at days 3 and 12 were fixed in $4 \%$ paraformaldehyde at $4^{\circ} \mathrm{C}$ for $24 \mathrm{~h}$; stained with hematoxylin eosin (HE) and observed by a light microscope (OLYMPUS BX43).

\section{Statistical Analysis}

All data were presented as the means \pm standard deviation (SD) and all statistical analyses were performed using GraphPad Prism software v8.0 (GraphPad Software, USA). Statistical significance of groups was analyzed using the one-way ANOVA and Tukey multiple comparison.

\section{RESULTS}

\section{In Vitro Antibacterial Activity MIC Assays}

As shown in Table 1, DLP4 showed the antibacterial activity against S. hyicus ACCC 61734 and S. hyicus NCTC 10350 with 
TABLE 1 | MIC assay of DLP4 and antibacterial agents against S. hyicus.

\begin{tabular}{lccccc}
\hline Antibacterial Agents & \multicolumn{2}{c}{$\boldsymbol{S}$. hyicus NCTC10350 } & & \multicolumn{2}{c}{ S. hyicus ACCC $\mathbf{6 1 7 3 4}$} \\
\cline { 2 - 3 } \cline { 5 - 6 } & $\boldsymbol{\mu}$ & $\boldsymbol{\mu} \mathbf{M} / \mathbf{m l}$ & & $\boldsymbol{\mu} \mathbf{M}$ & $\boldsymbol{\mu} \mathbf{g} / \mathbf{m l}$ \\
\hline DLP4 & 0.92 & 4 & & 0.92 & 4 \\
Ceftriaxone & 3.02 & 2 & & 6.04 & 4 \\
Ceftiofur & 12.08 & 8 & & 24.16 & 16 \\
Ofloxacin & 5.38 & 2 & & 43.2 & 16 \\
Amoxicillin & 2.38 & 1 & & 2.38 & 1 \\
Penicillin & 5.98 & 2 & & 2.99 & 1 \\
\hline
\end{tabular}

The unit of $\mu M$ means drug molar concentration; the unit of $\mu \mathrm{g} / \mathrm{m} /$ means drug mass concentration.

the MIC values of $0.92 \mu \mathrm{M}$. However, the tested antibiotics displayed low activity against S. hyicus ACCC 61734 and S. hyicus NCTC 10350, such as ceftriaxone with the MIC values over $3.02 \mu \mathrm{M}$ and ceftiofur with the MIC values over $12.08 \mu \mathrm{M}$, which were far higher than those of DLP4. The results indicated that DLP4, as the promising antimicrobial agent, displayed more potent antibacterial activity against $S$. hyicus.

\section{Bactericidal Kinetics}

The bactericidal kinetics of DLP4 against S. hyicus ACCC 61734 were shown in Figure 1A. In the blank control group, the $S$. hyicus cells reached $8.6 \log _{10} \mathrm{CFU} / \mathrm{ml}$ after cultured for $12 \mathrm{~h}$, and then entered into stationary phase. However, S. hyicus ACCC 61734 cells decreased dramatically after treatment with DLP4, and the bacteria were inhibited completely after treatment with $4 \times$ MIC DLP4 for $1 \mathrm{~h}$ and $2 \times$ MIC DLP 4 for $2 \mathrm{~h}$, and the bacteria were temporarily inhibited after treatment with $1 \times$ MIC DLP4 for $2 \mathrm{~h}$ but regrew after $12 \mathrm{~h}$, which demonstrated that DLP4 has dose-dependent growth inhibition against S. hyicus ACCC 61734 . In addition, the bactericidal rate of ceftriaxone $(2 \times$ MIC) apparently lagged, reduced slowly and even rebounded after incubation for $12 \mathrm{~h}$. These results indicated that DLP4 had the advantages of a rapid and non-rebounding activity compared with ceftriaxone.

\section{PAE}

As shown in Figure 1B, the PAE of DLP4 against S. hyicus ACCC 61734 was evaluated. The PAE values of DLP4 against S. hyicus ACCC 61734 were 9.54, 3.81, and $3.23 \mathrm{~h}$ at 4,2 , and $1 \times$ MIC, respectively, which were $28.9,11.5$, and 9.78 times longer than that of $2 \times$ MIC ceftriaxone $(0.33 \mathrm{~h})$, which indicated that the PAE effect of DLP4 was in a concentration dependent manner. The results indicated that DLP4 displayed a longer influence on the growth of S. hyicus ACCC 61734 than ceftriaxone.

\section{Synergy With Antibiotics}

The influence on efficiency of DLP4 in combination with several common antibiotics compared with their own individual activities was determined by FICI values. As shown in Table 2, the FICI values of combination of DLP4 with the tested
A

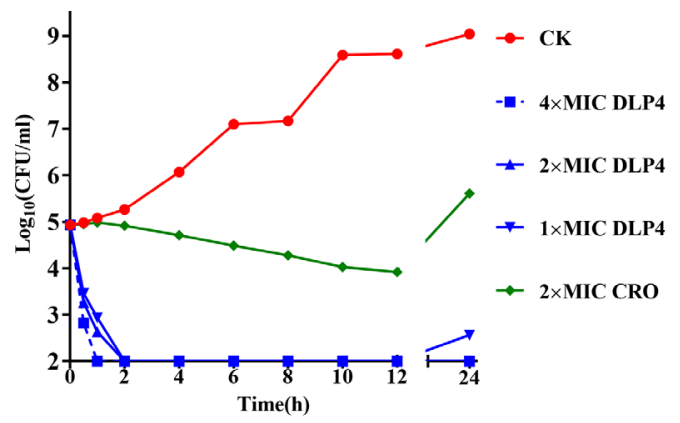

B

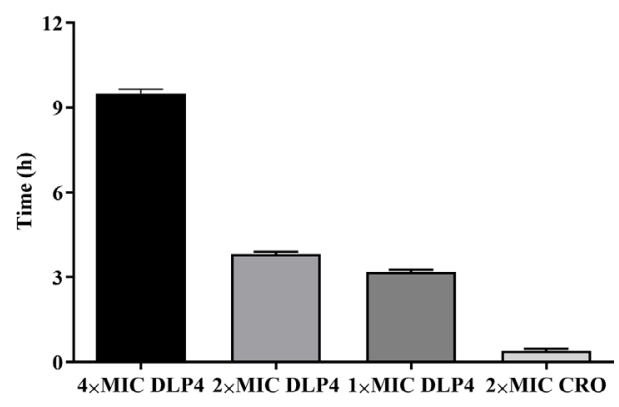

C

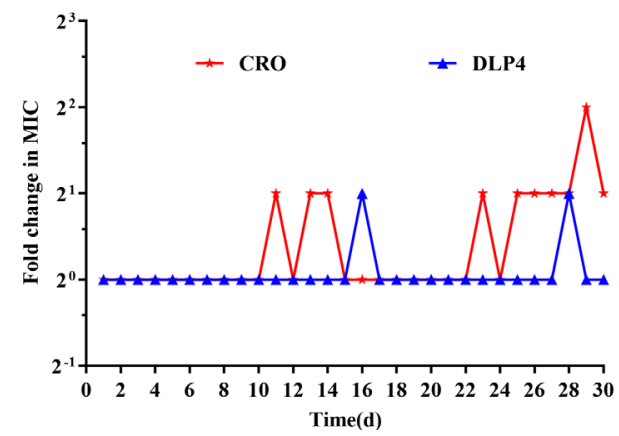

FIGURE 1 | In vitro antibacterial activity. (A) Time-kill curves of peptides and antibiotics against the S. hyicus ACCC 61734 in vitro. CK: S. hyicus ACCC 61734 was cultivated in culture medium without any drugs. Three duplicate observations were made, results were given as mean $\pm S D(n=3)$. (B) The PAE (h) of different doses of drugs. Results were given as mean $\pm S D(n=3)$. (C) Drug resistance evolution of $S$. hyicus cultured with sub-MIC DLP4 and ceftriaxone. 
TABLE 2 | The FICl of each combination of different antibiotics with DLP4.

S. hyicus ACCC 61734

\begin{tabular}{llcccc}
\hline Combination & Variety & $\mathbf{M I C}^{\mathbf{a}}(\boldsymbol{\mu} \mathbf{g} / \mathbf{m l})$ & $\mathbf{M I C}^{\mathbf{c}}(\boldsymbol{\mu} \mathbf{g} / \mathbf{m l})$ & $\mathbf{F I C}$ & $\mathbf{F I C l}$ \\
\hline \multirow{2}{*}{ DLP4-CRO } & DLP4 & 4 & 1 & 0.25 & $0.3125^{\mathrm{a}}$ \\
& CRO & 4 & 0.25 & 0.0625 & \\
DLP4-AMX & DLP4 & 4 & 0.5 & 0.125 & $0.375^{\mathrm{a}}$ \\
& AMX & 1 & 0.25 & 0.25 & \\
DLP4-PEN & DLP4 & 4 & 1 & 0.25 & $0.3125^{\mathrm{a}}$ \\
& PEN & 1 & 0.0625 & 0.0625 & \\
DLP4-OFX & DLP4 & 4 & 0.5 & 0.125 & $0.625^{\mathrm{b}}$ \\
& OFX & 16 & 8 & 0.5 & \\
\hline
\end{tabular}

$M I C^{a}$ indicates the MIC of drug used alone; MIC indicates the MIC of drug used in combination;

${ }^{a}$ Synergic effect; ${ }^{b}$ Additive effect.

antibiotics ceftriaxone, penicillin, amoxicillin and ofloxacin were $0.3125,0.3125,0.3725$, and 0.625 , respectively. According to the synergy index, the results showed that DLP4 displayed a synergy effect against $S$. hyicus when combined with ceftriaxone, penicillin and amoxicillin, and an additive effect when combined with ofloxacin. There was no indifference or antagonism, which may be due to the differences in antibacterial mechanisms between DLP4 and their antibacterial mechanisms were non-interfering each other.

\section{Resistance Induction Test}

As shown in Figure 1C, after 30 serial passages exposed to antibacterial drugs, the MIC of DLP4 against S. hyicus ACCC 61734 remained unchanged. While the MIC of ceftriaxone increased two times. These results displayed that both ceftriaxone and DLP4 are stable and not easy to develop drug resistance against S. hyicus ACCC 61734.

\section{Intracellular Bacteriostatic Efficacy}

As shown in Figure 2A, S. hyicus ACCC 61734 could successfully enter into HaCaT cells without destroying the cell membrane, and mainly located in the small vacuoles (tight phagosomes). At the same time, the bacteria were in a state of division, indicating that the bacteria could reproduce normally in the HaCaT cell, which was consistent with the previous results of S. aureus (Wang et al., 2018b). Meanwhile, the intracellular sterilization assay showed that DLP4 could enter into HaCaT cells and effectively kill S. hyicus ACCC 61734. Compared with the negative control group, the intracellular bactericidal rate after DLP4 treatment reached up to $99.9 \%$ (from 7.5 $\log _{10} \mathrm{CFU} / \mathrm{ml}$ to $3.6 \log _{10} \mathrm{CFU} / \mathrm{ml}$ ) (Figure 2B). And the results also showed that ceftriaxone did not kill the bacteria in $\mathrm{HaCaT}$ cells as it can't enter into cells.

\section{The Antibacterial Mechanism of DLP4 Integrity of Bacterial Membrane}

Based on its ability to permeate damaged cell membranes and insert into nucleic acid, PI staining was used to evaluate the effects of DLP4 on bacterial membrane by flow cytometry. As shown in Figure 3, in the absence of peptide, the percentage of S. hyicus ACCC 61734 stained with PI was $0.080 \%$. The PI-permeated percentages of cells treated with $1 \times$ MIC DLP4 were $0.403,2.28$, and $2.12 \%$ for 5,30 , and $120 \mathrm{~min}$, respectively, and those of cells treated with $2 \times$ MIC DLP4 were 1.56, 2.95, and $1.93 \%$ for 5, 30 and $120 \mathrm{~min}$, respectively, and those of cells treated with $4 \times$ MIC DLP4 were $1.93,2.95$ and $2.02 \%$ for 5,30 and $120 \mathrm{~min}$, respectively. The PI-permeated rate of DLP4 was similar with ceftriaxone (CRO)
A

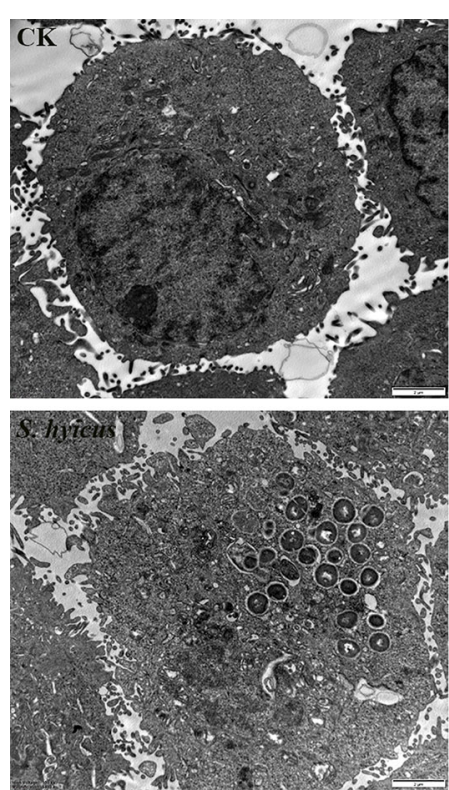

B

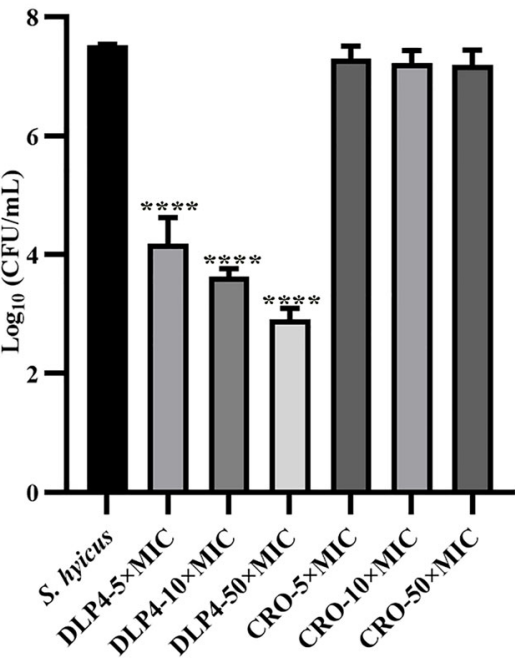

FIGURE 2 | Intracellular bacteriostatic efficacy of DLP4. (A) Morphologies of S. hyicus ACCC 61734 in HaCaT cells; (B) Intracellular antibacterial activity against S. hyicus ACCC 61734, results were given as mean $\pm S D(n=3)$. All data were analyzed by the one-way ANOVA and Bonferroni multiple comparison. ${ }^{* \star \star * P}<0.0001$. 
A

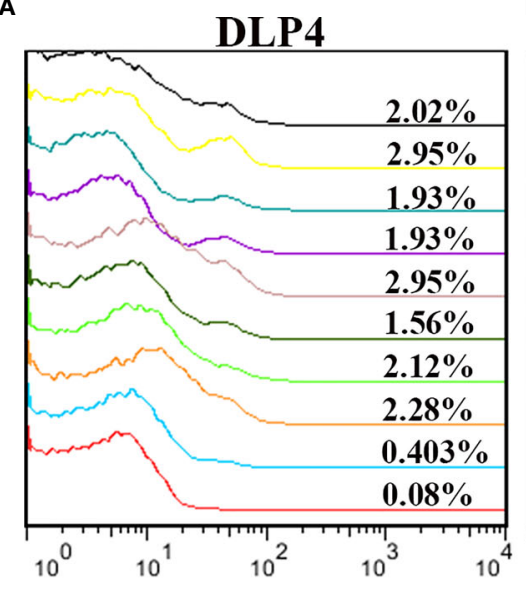

FL2-H

C

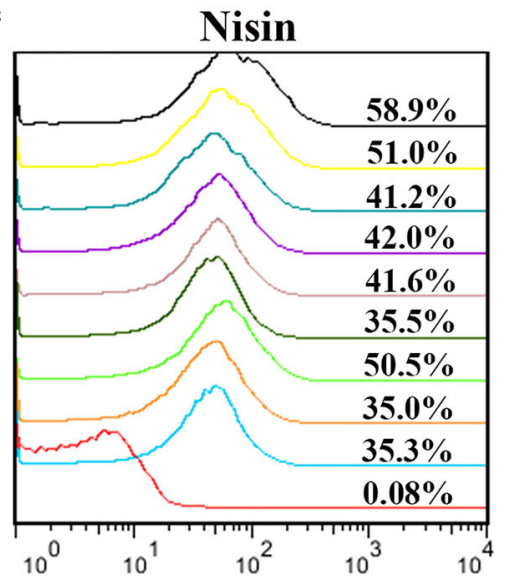

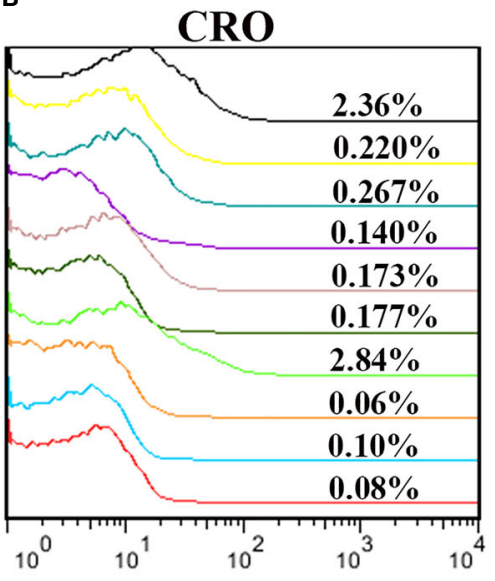

$\mathrm{FL} 2-\mathrm{H}$

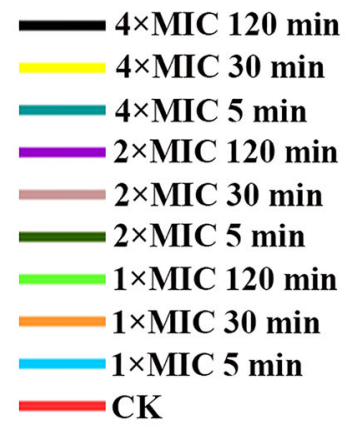

FIGURE 3 | Analysis of PI-staining in S. hyicus ACCC 61734 treated with DLP4. (A) Analysis of Pl-staining in S. hyicus ACCC 61734 treated with DLP4. (A) Pathogen treated with $1 \times, 2 \times$ and 4x MIC DLP4 for 5, 30 and 120 min, respectively; (B) Pathogen treated with 1×, 2x and 4x MIC CRO for 5, 30 and 120 min, respectively; (C) Pathogen treated with 1×, 2x and 4x MIC Nisin for 5, 30 and 120 min, respectively.

$(\leq 2.84 \%)$. The positive control nisin displayed the strong PIpermeated rate, which was $>35 \%$ even at $1 \times$ MIC for 5 min treatment. These results indicated that DLP4 has little effect on membrane integrity.

\section{SEM and TEM Observations}

SEM observations showed that the untreated S. hyicus ACCC 61734 cells were round and undamaged. While after incubation with $4 \times$ MIC DLP4, holes were observed in the bacterial peptidoglycan layer (cell wall), membrane vesicles were released resulting in the leakage of cellular contents. Moreover, amounts of shrinking cells and filiferous adhesions could also be observed (Figure 4A). The effect of DLP4 on S. hyicus ACCC 61734 was also visualized by TEM. As shown in Figure 4B, the untreated cells had intact membrane and their cytoplasm electron density appeared to be homogeneous. However, after treatment with DLP4, considerable changes were observed in cell morphology, the invagination of intracellular membrane, cell wall disruption and leakage of cellular content. Besides, the electron density became heterogeneous and a lot of ghost cells appeared in S. hyicus (approximately 95\%) (Figure 4B).

\section{Efficacy of DLP4 in a Mouse Model of Cutaneous Abscesses}

To verify the antibacterial efficacy of DLP4 on local infections, mice were subcutaneously infected with S. hyicus ACCC 61734 and followed by the treatment with DLP4, the efficacy of DLP4 was measured as described below.

\section{Observation of Abscess Symptoms}

The abscess symptom was monitored over the period of $12 \mathrm{~d}$ treatment and the abscess area was measured at 3, 7, and $12 \mathrm{~d}$. As shown in Figure 5A, during the entire healing period, DLP4 and ceftriaxone treatment all significantly reduced the scope of abscess and alleviated the symptom, especially the DLP4 treatment group, which showed no significant difference from that of the blank control group, while the negative control group showed limited self-recovery. The therapeutic effect of DLP4 and 


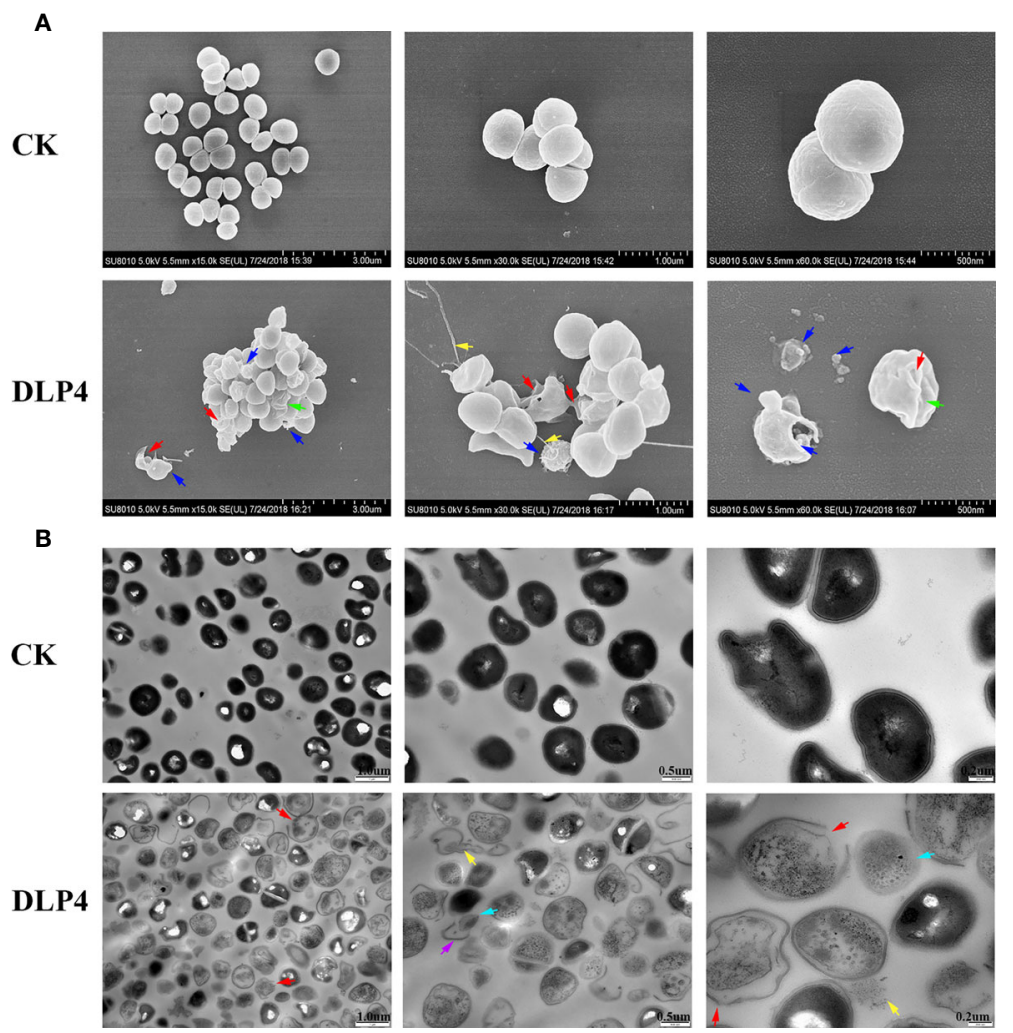

FIGURE 4 | Observation of the effect of DLP4 on the cell membrane and morphology of S. hyicus ACCC 61734. (A) SEM images of S. hyicus ACCC 61734 treated

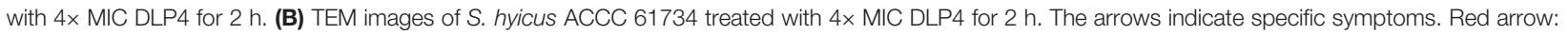
membrane perforation; blue arrow: membrane vesicles; yellow arrow: leakage of cytosol; green arrow: cell shrinkage; purple arrow: cell wall; cyan arrow: ghost cell.
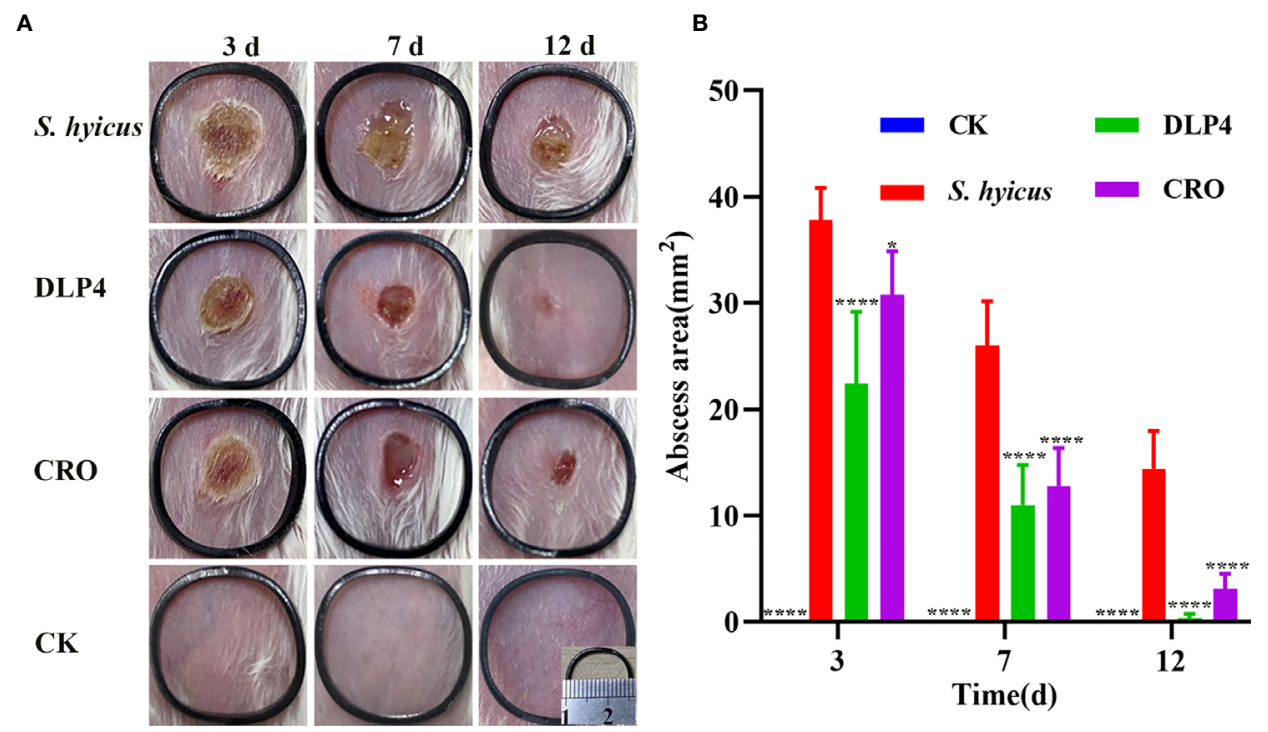

FIGURE 5 | The therapeutic effect of DLP4 in mouse model of cutaneous abscesses induced by S. hyicus ACCC 61734. Six weeks BALB/c mice were subcutaneously injected with S. hyicus ACCC 61734, and followed by the treatment with DLP4 and ceftriaxone (CRO) at $1 \mathrm{~d}$ after infection. (A) Photographs of abscess at days 3, 7, and 12 after challenge with S. hyicus ACCC 61734, the length and width of the black ring are $1.6 \mathrm{~cm}$. (B) The abscess area of different groups, results were given as mean $\pm S D(n=5)$, all data were analyzed by the one-way ANOVA and Bonferroni multiple comparison, ${ }^{\star} P<0.05$; ${ }^{\star \star \star \star} P<0.0001$. 
ceftriaxone were further illustrated by the size of abscess area, as shown in Figure 5B, at 3, 7, and 12 d, the average abscess areas of DLP4-treated mice were $22.4,11$, and $0.35 \mathrm{~mm}^{2}$, respectively, and ceftriaxone-treated mice were $30.8,12.8$, and $3.1 \mathrm{~mm}^{2}$, respectively, which were significantly smaller than those of the negative group $\left(37.8,26\right.$, and $14.4 \mathrm{~mm}^{2}$, respectively).

\section{Inhibition of Bacterial Translocation}

As a crucial evaluation of DLP4 efficacy, the bacterial burden of each abscess was determined. As shown in Figure 6A, compared with negative control group, the amount of bacterial in the abscesses of the DLP4 and ceftriaxone treated mice were significantly decreased, they were particularly manifested as the bacterial load of DLP4 treatment groups decreased by 24.3, 37.9, and $73.1 \%$ at days 3,7 , and 12 , respectively, which was slightly superior to ceftriaxone treatment group $(13.4,24.4$, and $55.8 \%$, respectively). The significant reduction of bacteria in groups treated with DLP4 and ceftriaxone were consistent with the results of the reduction in abscess area (Figure 5).

\section{Regulation of Cytokines}

To further investigate whether the protective effect of DLP4 was related to the regulation of inflammatory factors and epidermal growth factor, the skin lesions were collected to measure the levels of IL-6, TNF- $\alpha$, and EGF. As shown in Figures 6B, C, compared with the untreated group, the levels of IL-6 and TNF- $\alpha$ in DLP4-treated group decreased at 27.7, 69.4, 78.0, $37.2,67.6$, and $76.7 \%$ at days 3,7 , and 12 , respectively, which showed no significant difference compared with the ceftriaxonetreated group $(20.3,64.8,44.7,28.0,62.1$, and $63.5 \%$ at days 3,7 , and 12, respectively). Furthermore, compared with the untreated group, the expression of the EGF in DLP4-treated mice (146.7 and $220.7 \%$, respectively) and ceftriaxone-treated mice (39.6 and $108.9 \%$, respectively) prominently increased in the early stage ( 3 and $7 \mathrm{~d}$ ) but reduced quickly over time (54.0 and 31.5\%, $12 \mathrm{~d}$, respectively) (Figure 6D).

\section{Histopathology Analysis}

Histopathological assays of the abscess tissues were operated at 3, $12 \mathrm{~d}$ after infection with S. hyicus. As shown in Figure 7, skin lesions from negative-treated mice exhibited as: extensive inflammatory cells infiltrated, skin stratum spinosum was significantly thickened and keratinized, the dermis showed obvious purulent inflammatory necrotic lesions. Abscess symptoms gradually recovered with the time extension. Whereas, DLP4-treated and ceftriaxone-treated mice displayed

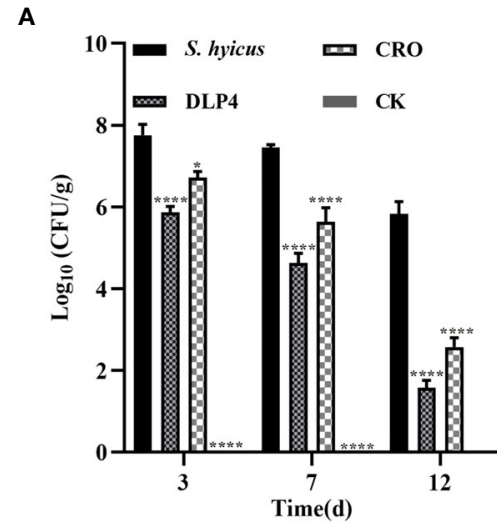

C

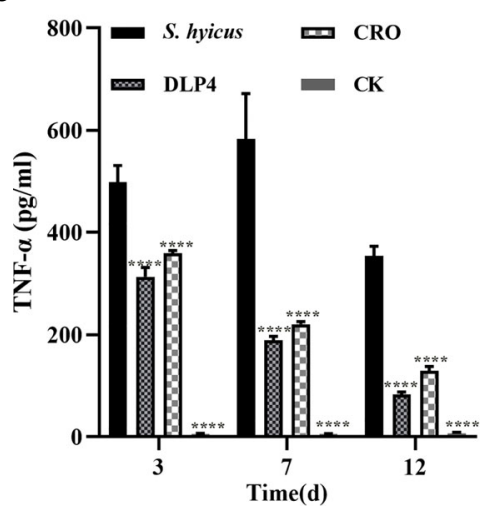

B

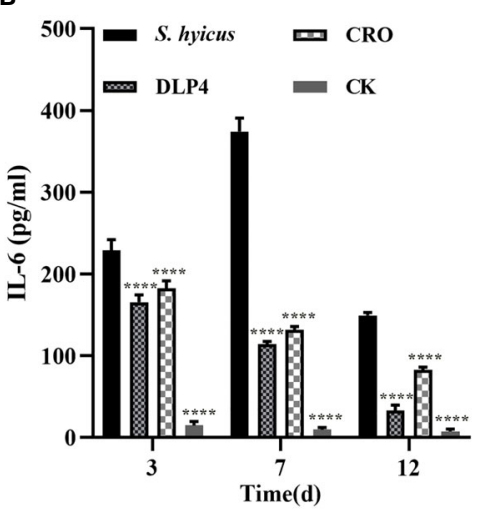

D

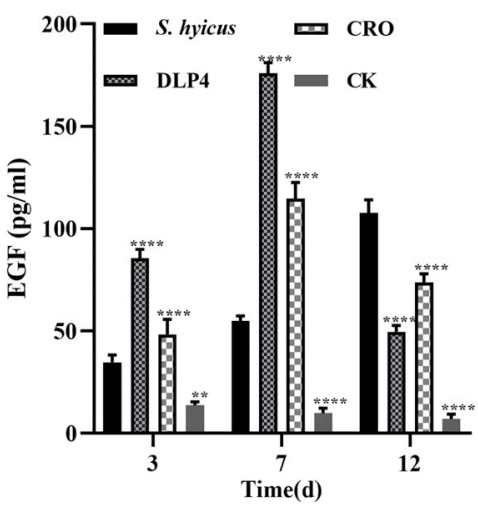

FIGURE 6 | The therapeutic effect of DLP4 in mouse model of cutaneous abscesses induced by S. hyicus ACCC 61734. (A) The effect of DLP4 or ceftriaxone (CRO) on bacterial burdens of cutaneous abscesses in S. hyicus-infected mice. Data are presented as mean \pm SD. (B-D) The regulatory effect of DLP4 or CRO on inflammatory factors (B) TNF- $\alpha$ (C) IL-6 and (D) epidermal growth factor (EGF). All data were analyzed by the one-way ANOVA and Bonferroni multiple comparison. ${ }^{\star} \mathrm{p}<$ $0.05,{ }^{\star \star} \mathrm{p}<0.01,{ }^{\star \star \star \star} \mathrm{p}<0.0001$. 

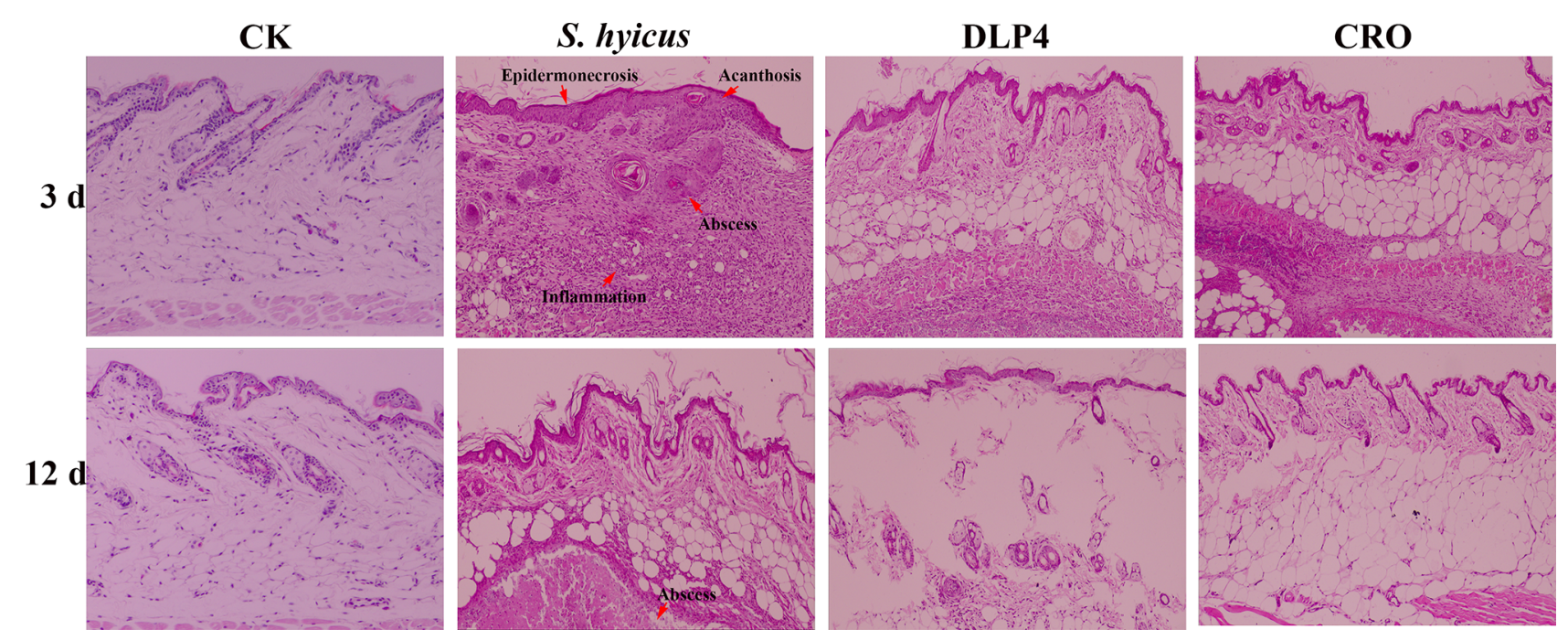

FIGURE 7 | The protective effect of DLP4 on mice skin lesion induced by S. hyicus ACCC 61734 . Histological assays of skin abscesses from mice (magnifications, $\times 100$ ) at 3 and 12 d. CK: the uninfected mice; S. hyicus: the infected mice without treatment; and treatment groups with DLP4 and ceftriaxone (CRO), respectively.

relatively moderate epidermal necrosis and cellulitis, which indicated that the mice treatment with DLP4 and ceftriaxone recovered rapidly.

\section{DISCUSSION}

In recent years, there is a great concern about the problem of bacterial resistance to antibiotics, which used in human medicine as well as in veterinary. Therefore, it is urgent to develop antibiotic alternatives to combat bacterial resistance. The prevention and control of S. hyicus infection is facing same problems (Park et al., 2013; Park et al., 2018). AMPs have shown great promise because they cause bacteria to develop no/low resistance. AMPs are produced by many organisms ranging from bacteria to fungi, plants, and animals, in particular, insect defensins have been considered as promising antibiotic alternatives, and their researches are getting more and more attention. In this study, the antibacterial activities, pharmacological characteristics, and in vitro mechanism of DLP4 against $S$. hyicus were systematically investigated.

Previous studies have shown that DLP4 exhibited a broad spectrum and high-efficiency bactericidal activity against Grampositive bacteria, including S. aureus, S. epidermidis, S. suis and S. hyicus, which can effectively prevent secondary infections of environmental microorganisms on the basis of skin damage (Park et al., 2015; Li et al., 2017) (Table 1). PAE is an important indicator of efficacy evaluation, reflecting the inhibitory effect of the drug on bacteria after a brief contact with bacteria (Bundtzen et al., 1981; Davoodi et al., 2020). In this study, the PAE of DLP4 against S. hyicus ACCC 61734 was almost 10 times than that of ceftriaxone at $2 \times$ MIC (Figure 1B), which may prolong the administration interval, reduce medical costs, and delay the occurrence of drug resistance. This study also proved that under long-term exposure to DLP4 at a subinhibitory concentration, S. hyicus ACCC 61734 was unlikely to develop drug resistance (Figure 1C), which further proved that DLP4 presented no/low resistance pharmacodynamic properties. Besides, DLP4 displayed a synergistic activity with $\beta$-lactam antibiotics (ceftriaxone, penicillin, and amoxicillin) against multi-drug resistant $S$. hyicus (Table 2). Ceftriaxone sodium, penicillin and amoxicillin inhibit the synthesis of bacterial cell wall by inhibiting D-alanyl-D-alanine transpeptidase, leading to bacterial death, which is the bactericide of breeding period, and ofloxacin leads to bacterial death by inhibiting the activity of bacterial DNA gyrase enzyme, preventing the synthesis and replication of bacterial DNA (Alves-Barroco et al., 2020). DLP4 and NZ2114 have the same tertiary structure, and belong to CS $\alpha \beta$ defensins, and the action of DLP4 and NZ2114 was on cell wall (Li et al., 2017). Study has indicated that plectasin NZ2114 was synergistic in combination with cell wall targeting antibiotics (teicoplanin, moenomycin, and dalbavancin) (Breidenstein et al., 2015), which provides an evidence for the synergistic effect of DLP4 and $\beta$-lactam antibiotics. The synergistic effects of DLP4 combination with antibiotics pave a novel way for the commercial application of insect defensin. The combination of insect defensins and antibiotics could restore sensitivity of multidrug-resistant pathogens, which will help to reduce the use of antibiotics and then delay the development of drug resistance (Dhand and Sakoulas, 2014; Mylonakis et al., 2016; Lazzaro et al., 2020).

Previous studies have shown that $S$. aureus can invade eukaryotic cells and evade the bactericidal action of conventional antibiotics (Wang et al., 2018a; Wang et al., 2018b; Li et al., 2020). This is the first study to prove that $S$. 
hyicus ACCC 61734 can be internalized by HaCaT cells, which help S. hyicus to evade conventional antibiotic killing (Figure 2). The corresponding conclusion was also obtained through this experiment, almost ceftriaxone does not have the ability to enter into cell, which was consistent with previous study (Prakash et al., 2013), which is due to its hydrophilicity, resulting in low cell penetration (Lipinski et al., 2001; Zaki and Hafez, 2012; Prakash et al., 2013). Since DLP4 and NZ2114 have the same molecular structure $\operatorname{CS} \alpha \beta$, we can reasonably to speculate that they share the same internalization mechanism: clathrin-mediated and polypinocytosis promote the accumulation of intracellular antimicrobial peptides and achieve effective sterilization (Wang et al., 2018b). It was further certified in this study: after treatment with DLP4, almost 99.9\% intracellular S. hyicus ACCC 61734 were killed, which was similar to previous study (Figure 2) (Li et al., 2020).

It has been proved that the mode of action of insect AMPs mainly focus on the interaction between AMP and bacterial cell membrane. This is mainly based on the cationic and hydrophobic characteristics, which make the insect AMP electrostatically attracted to the bacterial cell membrane, to establish connection, and further lead to the accumulation of hydrophobic residues, causing the outer leaves of the cell wall to swell and thin, and eventually form holes or even cause bacterial dissolution (Brown and Hancock, 2006; Mylonakis et al., 2016; Haney et al., 2017; Wang et al., 2021). In this study, the impacts of DLP4 on cell membrane were determined with FACS, SEM and TEM. The results indicated that the penetration rates of the DLP4 on membrane were controlled within $4 \%$ and did not have time and dose dependence, which is in consistent with previous study (Figure 3) ( $\mathrm{Li}$ et al., 2017), and SEM and TEM images displayed amounts of shrinking cells, invagination of intracellular membrane and a lot of ghost cells. This phenomenon may be explained by the "bubbling cell death" triggered by DLP4, which manifested by DLP4 weakening cell wall, forming holes in the peptidoglycan, stimulating the formation of cytoplasmic vesicles, and thus leading to release of the membrane vesicles and form ghost cells (Figure 4A) (Toyofuku et al., 2019). While the underlying molecular mechanism is not clear, which may be related to conservative residues Asp4 and Arg23, which need to be further proved. (Brogden, 2005; Cerovsky et al., 2011; Li et al., 2017).

Previous studies have indicated that AMPs not only have highefficiency bactericidal functions, but also have immunoregulatory function, such as LL-37 and HBD2 (Funderburg et al., 2007; Semple et al., 2011; Tewary et al., 2013). To explore the immunomodulatory activities of DLP4, a mouse abscess model was established, as the healing of skin abscess is a complex, coordinated and orderly process to promote tissue repair and regenerate, there are a variety of cells and cytokines participate in the process (Rousselle et al., 2018; Hou et al., 2020). In this study, after challenged with S. hyicus ACCC 61734, humoral immunity and celluar immunity were rapidly activated to protect mice from fatal injury. After treatment with DLP4, the levels of TNF- $\alpha$, IL-6 decreased (Figures 6B, C), the level of EGF significantly increased and followed by a decreased with the extension of treatment time
(Figure 6D). TNF- $\alpha$, as the initiator of tissue repair, is a potent stimulator of chemotaxis and degradative responses required for wound healing, and it can accelerate the wound healing. When infected by S. hyicus ACCC 61734, macrophages, mast cells and keratinocytes were activated, which can further promote the differentiation of $\mathrm{T}$ cells and the release of TNF- $\alpha$ and IL-6, further attract and activate neutrophils and monocytes, inducing fibroblasts to produce prostaglandin E (PGE) and collagenase. Simultaneously, EGF is a mitotic stimulator. After binding to receptors on the cell membrane of skin tissues, EGF induces or directly regulates important genes for cell proliferation through autophosphorylation, and stimulates the division and proliferation of damaged cells, further initiates wound repair, and strongly promotes the growth of epithelial cells effect (Schultz et al., 2004). Consistent with this, DLP4 possesses substantial wound healing properties in mice, which may be based on its ability to balance cytokine release, while the immune regulation and function need to be further confirmed through cell signaling pathway (Mylonakis et al., 2016).

\section{CONCLUSION}

In this study, in vitro and in vivo multiple effects of DLP4 against S. hyicus ACCC 61734 were systematically investigated. DLP4 displayed excellent antibacterial and pharmacological activity and killed S. hyicus ACCC 61734 cells by destroying cell wall and generating membrane vesicles. In vivo experimental results showed that DLP4 displayed potent therapeutic effect on mouse abscess by inhibiting bacterial proliferation and regulating cytokines. All results provide evidence that DLP4 may be used as promising drug for the treatment of EE caused by $S$. hyicus ACCC 61734.

\section{DATA AVAILABILITY STATEMENT}

The original contributions presented in the study are included in the article/supplementary material. Further inquiries can be directed to the corresponding authors.

\section{ETHICS STATEMENT}

The animal study was reviewed and approved by the Laboratory Animal Ethical Committee and its Inspection of the Feed Research Institute of CAAS (AEC-CAAS-20090609).

\section{AUTHOR CONTRIBUTIONS}

$\mathrm{XM}, \mathrm{NY}$, and DT: conception and experiments design. XM: experiments operation. XM, NY, RM, and YH: methodology and data analysis. XM: writing-original draft. JW, NY, and DT: 
writing - review and editing. JW and XY: contributed in funding acquisition. All authors contributed to the article and approved the submitted version.

\section{FUNDING}

This study was supported by the National Natural Science Foundation of China (No. 31872393), the Agricultural Science and Technology Innovation Program (ASTIP) in CAAS (CAASZDXT2018008 and CAAS-ASTIP-2013-FRI-02), and grant

\section{REFERENCES}

Alves-Barroco, C., Rivas-García, L., Fernandes, A. R., and Baptista, P. V. (2020). Tackling Multidrug Resistance in Streptococci-from Novel Biotherapeutic Strategies to Nanomedicines. Front. Microbiol. 11, 1-13. doi: 10.3389/ fmicb.2020.579916

Andresen, L. O., and Ahrens, P. (2004). A Multiplex PCR for Detection of Genes Encoding Exfoliative Toxins From Staphylococcus Hyicus. J. Appl. Microbiol. 96, 1265-1270. doi: 10.1111/j.1365-2672.2004.02258.x

Andresen, L. O., Wegener, H. C., and Bille-Hansen, V. (1993). Staphylococcus Hyicus-Skin Reactions in Piglets Caused by Crude Extracellular Products and by Partially Purified Exfoliative Toxin. Microb. Pathog. 15, 217-225. doi: 10.1006/mpat.1993.1072

Arsenakis, I., Boyen, F., and Haesebrouck, F. (2018). Autogenous Vaccination Reduces Antimicrobial Usage and Mortality Rates in a Herd Facing Severe Exudative Epidermitis Outbreaks in Weaned Pigs. Vet. Rec. 182 (26), 744. doi: $10.1136 / v r .104720$

Breidenstein, E., Courvalin, P., and Meziane-Cherif, D. (2015). Antimicrobial Activity of Plectasin NZ2114 in Combination With Cell Wall Targeting Antibiotics Against Vana-Type Enterococcus Faecalis. Microb. Drug Resist. 21 (4), 373-379. doi: 10.1089/mdr.2014.0221

Brogden, K. A. (2005). Antimicrobial Peptides: Pore Formers or Metabolic Inhibitors in Bacteria? Nat. Rev. Microbiol. 3, 238-250. doi: 10.1038/ nrmicro1098

Brown, K. L., and Hancock, R. E. (2006). Cationic Host Defense (Antimicrobial) Peptides. Curr. Opin. Immunol. 18, 24-30. doi: 10.1016/j.coi.2005.11.004

Bundtzen, R. W., Gerber, A. U., Cohn, D. L., and Craig, W. A. (1981). Postantibiotic Suppression of Bacterial Growth. Rev. Infect. Dis. 3 (1), 28-37. doi: $10.1093 /$ clinids/3.1.28

Ceřovský, V., Slaninová, J., Fučík, V., Monincová, L., Bednárová, L., Maloň, P., et al. (2011). Lucifensin, a Novel Insect Defensin of Medicinal Maggots: Synthesis and Structural Study. Chembiochem. 12, 1352-1361. doi: 10.1002/ cbic. 201100066

Davoodi, S., Daryaee, F., Chang, A., Walker, S. G., and Tonge, P. J. (2020). Correlating Drug-Target Residence Time and Post-Antibiotic Effect: Insight Into Target Vulnerability. Acs. Infect. Dis. 6, 629-636. doi: 10.1021/ acsinfecdis.9b00484

Dhand, A., and Sakoulas, G. (2014). Daptomycin in Combination With Other Antibiotics for the Treatment of Complicated Methicillin-Resistant Staphylococcus Aureus Bacteremia. Clin. Ther. 36, 1303-1316. doi: 10.1016/ j.clinthera.2014.09.005

Ding, Y., Fu, Y., Lee, J. C., and Hooper, D. C. (2012). Staphylococcus Aureus NorD, a Putative Efflux Pump Coregulated With the Opp1 Oligopeptide Permease, Contributes Selectively to Fitness In Vivo. J. Bacteriol. 194, 65866593. doi: 10.1128/JB.01414-12

Fudaba, Y., Nishifuji, K., Andresen, L. O., Yamaguchi, T., and Sugai, M. (2005). Staphylococcus Hyicus Exfoliative Toxins Selectively Digest Porcine Desmoglein 1. Microb. Pathog. 39, 171-176. doi: 10.1016/j.micpath.2005.08.003

Funderburg, N., Lederman, M. M., Feng, Z., Drage, M. G., Jadlowsky, J., Harding, C. V., et al. (2007). Human -Defensin-3 Activates Professional AntigenPresenting Cells Via Toll-like Receptors 1 and 2. Proc. Natl. Acad. Sci. U. S. A. 104, 18631-18635. doi: 10.1073/pnas.0702130104
NH2021202202 of the Quality Control for Feed and Products of Livestock and Poultry Key Laboratory of Sichuan Province.

\section{ACKNOWLEDGMENTS}

We acknowledge Minhua Yan from Animal Husbandry Institute of Tianjin Academy of Agricultural Sciences for donating $S$. hyicus ACCC 61734. We acknowledge Tong Zhao and Jingnan Liang from the Core Facility at the Institute of Microbiology at the Chinese Academy of Sciences (CAS) for their technical support with the flow cytometric, TEM and SEM analyses.

Hanakawa, Y., Schechter, N. M., Lin, C., Garza, L., Li, H., Yamaguchi, T., et al (2002). Molecular Mechanisms of Blister Formation in Bullous Impetigo and Staphylococcal Scalded Skin Syndrome. J. Clin. Invest. 110, 53-60. doi: 10.1172/JCI15766

Hancock, R. E. W., and Sahl, H. G. (2006). Antimicrobial and Host-Defense Peptides as New Anti-Infective Therapeutic Strategies. Nat. Biotechnol. 24, 1551-1557. doi: 10.1038/nbt1267

Haney, E. F., Mansour, S. C., and Hancock, R. E. W. (2017). Antimicrobial Peptides: An Introduction. Methods Mol. Biol. 1548, 3-22. doi: 10.1007/978-14939-6737-7_1

Hao, Y., Yang, N., Wang, X., Teng, D., Mao, R., Wang, X., et al. (2017). Killing of Staphylococcus Aureus and Salmonella Enteritidis and Neutralization of Lipopolysaccharide by 17-Residue Bovine Lactoferricins: Improved Activity of Trp/Ala-containing Molecules. Sci. Rep. 7, 44278. doi: 10.1038/srep44278

Holmer, I., Salomonsen, C. M., Jorsal, S. E., Astrup, L. B., Jensen, V. F., Høg, B. B., et al. (2019). Antibiotic Resistance in Porcine Pathogenic Bacteria and Relation to Antibiotic Usage. BMC Vet. Res. 15 (1), 449. doi: 10.1186/s12917-019-2162-8

Hou, S., Liu, Y., Feng, F., Zhou, J., Feng, X., and Fan, Y. (2020). PolysaccharidePeptide Cryogels for Multidrug-Resistant-Bacteria Infected Wound Healing and Hemostasis. Adv. Healthc. Mater. 9 (3), e1901041. doi: 10.1002/ adhm.201901041

Lazzaro, B. P., Zasloff, M., and Rolff, J. (2020). Antimicrobial Peptides: Application Informed by Evolution. Science 368, eaau5480. doi: 10.1126/science.aau5480

Li, Z., Mao, R., Teng, D., Hao, Y., Chen, H., and Wang, J. (2017). Antibacterial and Immunomodulatory Activities of Insect defensins-DLP2 and DLP4 Against Multidrug-Resistant Staphylococcus Aureus. Sci. Rep. 7 (1), 12124. doi: 10.1038/ s41598-017-10839-4

Lipinski, C. A., Lombardo, F., Dominy, B. W., and Feeney, P. J. (2001). Experimental and Computational Approaches to Estimate Solubility and Permeability in Drug Discovery and Development Settings. Adv. Drug Deliv. Rev. 46, 3-26. doi: 10.1016/s0169-409x(00)00129-0

Li, B., Yang, N., Shan, Y., Wang, X., and Wang, J. (2020). Therapeutic Potential of a Designed Cs $\alpha \beta$ Peptide ID13 in Staphylococcus Aureus-Induced Endometritis of Mice. Appl. Microbiol. Biotechnol. 104 (15), 6693-6705. doi: 10.1007/s00253-020-10685-x

Mariutti, R. B., Souza, T., Ullah, A., Caruso, I. P., de Moraes, F. R., Zanphorlin, L. M., et al. (2015). Crystal Structure of Staphylococcus Aureus Exfoliative Toxin D-like Protein: Structural Basis for the High Specificity of Exfoliative Toxins. Biochem. Biophys. Res. Commun. 467, 171-177. doi: 10.1016/j.bbrc.2015.08.083

Ma, X., Wang, J., Ren, W., Teng, D., Chi, J., Wang, X., et al. (2019). Establishment of Model of Exudative Dermatitis of Piglets Infected With Clinical Isolated Staphylococcus Hyicus. China Anim. Husb Vet Med. 046, 2110-2118. doi: 10.16431/j.cnki.1671-7236.2019.07.028

Mylonakis, E., Podsiadlowski, L., Muhammed, M., and Vilcinska, A. (2016). Diversity, Evolution and Medical Applications of Insect Antimicrobial Peptides. Philos. Trans. R. Soc Lond. B. Biol. Sci. 371 (1695), 20150290. doi: 10.1098/rstb.2015.0290

Narayana, J. L., Huang, H. N., Wu, C. J., and Chen, J. Y. (2015). Efficacy of the Antimicrobial Peptide TP4 Against Helicobacter Pylori Infection: In Vitro Membrane Perturbation Via Micellization and In Vivo Suppression of Host Immune Responses in a Mouse Model. Oncotarget. 6, 12936-12954. doi: 10.18632/oncotarget.4101 
Nishifuji, K., Fudaba, Y., Yamaguchi, T., Iwasaki, T., Sugai, M., and Amagai, M. (2005). Cloning of Swine Desmoglein 1 and its Direct Proteolysis by Staphylococcus Hyicus Exfoliative Toxins Isolated From Pigs With Exudative Epidermitis. Vet. Dermatol. 16, 315-323. doi: 10.1111/j.1365-3164.2005.00474.x

Nishifuji, K., Sugai, M., and Amagai, M. (2008). Staphylococcal Exfoliative Toxins: "Molecular Scissors" of Bacteria That Attack the Cutaneous Defense Barrier in Mammals. J. Dermatol. Sci. 49, 21-31. doi: 10.1016/j.jdermsci.2007.05.007

Olivry, T., and Linder, K. E. (2009). Dermatoses Affecting Desmosomes in Animals: A Mechanistic Review of Acantholytic Blistering Skin Diseases. Vet. Dermatol. 20, 313-326. doi: 10.1111/j.1365-3164.2009.00821.x

Park, J. E., Easwaran, M., Park, J. W., and Shin, H. J. (2018). Antimicrobial Susceptibility of Staphylococcus Hyicus Isolated From Korean Pigs With Exudative Epidermitis. J. Prev. Vet. Med. 42 (1), 41-45. doi: 10.1304/ jpvm.2018.42.1.41

Park, J., Friendship, R. M., Poljak, Z., Weese, J. S., and Dewey, C. E. (2013). An Investigation of Exudative Epidermitis (Greasy Pig Disease) and Antimicrobial Resistance Patterns of Staphylococcus Hyicus and Staphylococcus Aureus Isolated From Clinical Cases. Can. Vet. J. La Rev. vet. Can. 54, 139-144.

Park, S. I., Kim, J. W., and Yoe, S. M. (2015). Purification and Characterization of a Novel Antibacterial Peptide From Black Soldier Fly (Hermetia Illucens) Larvae. Dev. Comp. Immunol. 52, 98-106. doi: 10.1016/j.dci.2015.04.018

Prakash, G. D., Midhun, B. T., Monalisha, E., Raichur, A. M., and Dipshikha, C. (2013). Chitosan-Dextran Sulphate Nanocapsule Drug Delivery System as an Effective Therapeutic Against Intraphagosomal Pathogen Salmonella. J. Antimicrob. Chemother. 68, 2576-2586. doi: 10.1093/jac/dkt252

Rousselle, P., Montmasson, M., and Garnier, C. (2018). Extracellular Matrix Contribution to Skin Wound Re-Epithelialization. Matrix Biolo. 75-76, $12-$ 26. doi: 10.1016/j.matbio.2018.01.002

Schultz, G., Clark, W., and Rotatori, D. S. (2004). EGF and TGF- $\alpha$ in Wound Healing and Repair. J. Cell. Biochem. 45, 346-352. doi: 10.1002/jcb.240450407

Semple, F., MacPherson, H., Webb, S., Cox, S. L., Mallin, L. J., Tyrrell, C., et al. (2011). Human $\beta$-Defensin 3 Affects the Activity of Pro-Inflammatory Pathways Associated With MyD88 and TRIF. Eur. J. Immunol. 41, 32913300. doi: 10.1002/eji.201141648

Tewary, P., de la Rosa, G., Sharma, N., Rodriguez, L. G., Tarasov, S. G., Howard, O. M., et al. (2013). $\beta$-Defensin 2 and 3 Promote the Uptake of Self or CpG DNA, Enhance IFN- $\alpha$ Production by Human Plasmacytoid Dendritic Cells, and Promote Inflammation. J. Immunol. 191, 865-874. doi: 10.4049/jimmunol.1201648

Toyofuku, M., Nomura, N., and Eberl, L. (2019). Types and Origins of Bacterial Membrane Vesicles. Nat. Rev. Microbiol. 17 (1), 13-24. doi: 10.1038/s41579018-0112-2
Wang, Z., Kong, L., Liu, Y., Fu, Q., Cui, Z., Wang, J., et al. (2018a). A Phage Lysin Fused to a Cell-Penetrating Peptide Kills Intracellular Methicillin-Resistant Staphylococcus Aureus in Keratinocytes and has Potential as a Treatment for Skin Infections in Mice. Appl. Environ. Microbiol. 84 (12), e00380-e00318. doi: 10.1128/AEM.00380-18

Wang, X., Wang, X., Teng, D., Mao, R., Hao, Y., Yang, N., et al. (2018b). Increased Intracellular Activity of MP1102 and NZ2114 Against Staphylococcus Aureus In Vitro and In Vivo. Sci. Rep. 8, 4204. doi: 10.1038/s41598-018-22245-5

Wang, C. S., Shao, C. X., Fang, Y. X., Wang, J. J., Dong, N., and Shan, A. S. (2021). Binding Loop of Sunflower Trypsin Inhibitor 1 Serves as a Design Motif for Proteolysis-Resistant Antimicrobial Peptides. Acta Biomater. 124, 254-269. doi: 10.1016/j.actbio.2021.01.036

Zaki, N. M., and Hafez, M. M. (2012). Enhanced Antibacterial Effect of Ceftriaxone-Loaded Chitosan Nanoparticles Against Intracellular Salmonella Typhimurium. AAPS PharmSciTech. 13, 411-421. doi: 10.1208/s12249-0129758-7

Zhang, Y., Teng, D., Mao, R., Wang, X., Xi, D., Hu, X., et al. (2014). High Expression of a Plectasin-Derived Peptide NZ2114 inPichia Pastorisand its Pharmacodynamics, Postantibiotic and Synergy Against Staphylococcus Aureus. Appl. Microbiol. Biotechnol. 98, 681-694. doi: 10.1007/s00253-0134881-2

Zhao, F., Yang, N., Wang, X. M., Mao, R. Y., Hao, Y., Li, Z. Z., et al. (2019). In Vitro/Vivo Mechanism of Action of MP1102 With Low/Nonresistance Against Streptococcus Suis Type 2 Strain CVCC 3928. Front. Cell. Infect. Mi. 9, 1-13. doi: $10.3389 /$ fcimb.2019.00048

Zheng, X., Wang, X., Teng, D., Mao, R., and Wang, J. (2017). Mode of Action of Plectasin-Derived Peptides Against Gas Gangrene-Associated Clostridium Perfringens Type a. PloS One 12, e0185215. doi: 10.1371/journal.pone.0185215

Conflict of Interest: Author XY was employed by New hope Liuhe Co., Ltd.

The remaining authors declare that the research was conducted in the absence of any commercial or financial relationships that could be construed as a potential conflict of interest.

Copyright (c) $2021 \mathrm{Ma}$, Yang, Mao, Hao, Yan, Teng and Wang. This is an open-access article distributed under the terms of the Creative Commons Attribution License (CC BY). The use, distribution or reproduction in other forums is permitted, provided the original author(s) and the copyright owner(s) are credited and that the original publication in this journal is cited, in accordance with accepted academic practice. No use, distribution or reproduction is permitted which does not comply with these terms. 